\title{
LA DESINFORMACIÓN \\ Y LA BÚSQUEDA DE RESPUESTAS PARA ENFRENTARLA
}

María del Luján Flores*

RESUMEN. El mundo actual nos enfrenta a una paradoja, por un lado el desarrollo de la tecnología posibilita un mayor acceso, verificación y difusión de la información, imprescindibles en una democracia y por otro se da una proliferación de falsas noticias, un afán por captar audiencias y manipular la opinión pública fundamentalmente con fines políticos y económicos.

El artículo se refiere al impacto de la desinformación en la sociedad y al conflicto de derechos que crea. La preocupación por las consecuencias negativas que produce y las respuestas que desde el punto de vista jurídico se han dado tanto a nivel internacional, regional como individual por parte de algunos Estados.

PALABRAS CLAVES. Desinformación. Verdad. Conflictos de derechos. Libertad de expresión.

ABSTRACT. Today's world faces a paradox: on the one hand the development of technology allows greater access, verification and disclosure of information, essential in a democracy; and on the other hand, there is a proliferation of fake news, an effort to capture public opinion primarily for political and economic purposes.

This paper refers to the impact of disinformation on society and the conflict of rights it creates. Concern about the negative consequences it produces are explored, as well as the responses that have been given at international, regional and individual levels by some States.

KEY WORDS. Disinformation. Truth. Conflict of rights. Freedom of expression.

*Doctora en Derecho y Ciencias Sociales. Ex docente de Derecho Internacional Público, Facultad de Derecho, UDELAR. Correo electrónico: maria_flores_n@hotmail.com 
La influencia de los medios de comunicación en la estructura de la sociedad actual es un fenómeno que dista aún de ser percibido en su cabal dimensión. La repercusión que la tecnología en materia de comunicación opera en el entramado de la sociedad en determinadas circunstancias genera períodos de confusión. Pese al desarrollo de estos medios y a su indudable gravitación se los reduce como bien se ha señalado a meros vehículos de transmisión informativa desconociendo que en su conjunto configuran la denominada "modernidad", en el sentido de creación de nuevas formas de acción e interacción en la sociedad, nuevos tipos de relaciones sociales y de relacionarse con los otros y con uno mismo. ${ }^{1}$

El uso que se da a los medios de comunicación para alcanzar "la verdad" es la piedra de toque, la manera en que se construye y comunica a través de estos es fundamental para determinar la legalidad o no de la acción, en última instancia si se respetan o no los derechos humanos.

A vía de ejemplo, dos casos paradigmáticos como el de Dreyfus en 1894 y el de Snowden en 2013 con sus semejanzas y diferencias marcan hitos que reflejan el papel del periodismo como contrapeso de la presión ejercida por el poder y su aporte a la sociedad democrática. ${ }^{2}$

En la orilla opuesta encontrarnos una práctica cada vez más frecuente la de las noticias falsas; noticias falsas que como bien lo dice el adjetivo no son tales ya que pueden revestir la forma de noticias pero en el fondo no lo son.

El mundo actual nos enfrenta a una serie de paradojas una de ellas es el auge y para algunos filósofos la novedad del fenómeno de la pos verdad. El desarrollo o avance de la tecnología nos aproxima a la construcción de democracias basadas en información accesible, confiable, veraz, posible de comprobar y por otro lado se da una proliferación de falsedades, un tráfico de noticias donde persiste una carrera permanente por captar seguidores que trasciende la competencia tradicional. La verdad deja de ser el producto de testimonios contrastados para convertirse en el veredicto constante de audiencia. ${ }^{3}$

Verdad, imparcialidad y justicia son ideales, valores inalcanzables, aspiraciones, cuya búsqueda debe ser permanente. Se dice que se aspira a ellos pero lo que es real es la mentira, la tergiversación intencionada, la injusticia y la inequidad. ${ }^{4}$

La manipulación de la verdad es tan antigua como el hombre pero fue en el año 2016 que acaparó la atención de la opinión pública al ser nominada por los diccionarios Oxford como palabra de ese año. Ella es definida como aquello que se relaciona con o denota circunstancias en las que los hechos objetivos son menos influyentes a la hora de conformar la opinión pública que las apelaciones a la emoción y a las creencias personales. El prefijo "pos" tendría por finalidad mas que indicar un sentido temporal de que algo quedó atrás el que la verdad es irrelevante. ${ }^{5}$

1 THOMPSON, John. Los medios y la modernidad. Una teoría de los medios de comunicación. Barcelona: Paidós, 1998, p. 15 y ss.

${ }^{2}$ MAZZONE, Daniel. El periodismo, un convidado de piedra en el sistema de pesos y contrapesos en Diálogo Político. Konrad Adenauer Stiftung. Ciencia y Política. Montevideo: abril 2016, p. 125 y ss.

${ }^{3}$ BLATT, Roberto. Historia reciente de la verdad. Turner Publicaciones S.L., setiembre de 2018. Madrid, p. 103-105.

${ }^{4}$ BILINKIS, Santiago. «La verdad no existe pero la mentira sí». Revista La Nación, 2017.

${ }^{5}$ MC INTYRE, Lee. Posverdad. Cátedra Teorema. Madrid, p. 31 y ss. 
Lo paradójico radica en que en una época en que existe una gran difusión y expansión de la información, una accesibilidad mayor a la cultura, a la posibilidad de conocer en forma casi instantánea lo que sucede en distintos puntos del planeta y manejar simultáneamente distintos medios de comunicación, las noticias falsas, la falta de veracidad, de sentido común y ausencia de espíritu crítico, proliferan. El desdén por los hechos, por la verdad que implica la pos verdad va más allá de la mentira clásica o tradicional que busca ocultar o presentar los hechos de manera diferente a la realidad, porque quien incurre en ella reconoce la importancia que existe, es conciente de la diferencia que provoca con su accionar. Por el contrario para el concepto de pos verdad o verdad posterior los hechos no están conectados con la realidad, lo que interesa no son los hechos, no se les presta atención, no hay preocupación por ocultarlos o deformar la realidad, simplemente se ignora a la verdad. Las campañas de desinformación, de deformación de la realidad hoy día se multiplican, los datos se matizan y seleccionan, se hacen coincidir con conceptos que lleven a primar una posición sobre otra. La lista es interminable. La tecnología nos aproxima a la concreción de una democracia ${ }^{6}$ basada en información contrastada las evidencias se hacen accesibles pero las falsedades se convierten en moneda corriente. El tráfico es la medida de la importancia de las noticias.

El propósito es espurio y puede responder tanto al deseo de manipular la opinión pública con fines políticos como a lograr beneficios económicos, entre otras razones. La Comisión Europea en 2018 definió a la desinformación como información verificablemente falsa o engañosa que se crea, presenta y divulga para obtener beneficios económicos o para engañar intencionalmente al público y que puede causar daño a este último. El perjuicio público comprende amenazas contra los procesos democráticos y bienes públicos como la salud, el medio ambiente o la seguridad.

En general estas informaciones fueron publicadas en medios digitales y no han sido verificadas, carecen de fuentes que esten identificadas. Su objetivo es influir en la opinión pública creando desestabilización o descrédito. Las noticias falsas provienen de sitios ficticios diseñados para parecer fiables y en general producen títulos sensacionalistas para atraer al lector. Quienes se ven directamente afectados e involucrados al producirse estos hechos son los derechos humanos. A ellos nos referiremos a continuación.

${ }^{6}$ La "tercera ola de democratización" que se inició en la década de los setenta se aceleró con la caída del muro de Berlín y el fin de la Guerra Fría. Tuvo sus comienzos en Europa y luego se expandió a Latinoamérica y otros continentes. A nivel multilateral también se tomó conciencia de la importancia de fortalecer la gobernabilidad democrática y su estrecha vinculación con la paz y los derechos humanos. En este sentido en la Declaración Universal de Derechos Humanos de 1948 se contemplan los derechos políticos que deben regir en el marco de una sociedad democrática. En el marco de los Pactos Internacionales de Derechos Civiles y Políticos y Derechos Económicos, Sociales y Culturales de 1966 el Comité de Derechos Humanos de la ONU se refirió a un derecho colectivo a la democracia. Asimismo en instrumentos como la Declaración del Milenio del año 2000 se introducen menciones a la defensa de la libertad, la democracia y el estado de derecho y en distintos foros mundiales se realizan seguimientos de los avances democráticos. Todo lo cual marca la diferencia que se dio entre el ámbito universal y el regional. En efecto, los fundadores de las Naciones Unidas no hicieron referencia a la democracia en la Carta mientras que en el ámbito regional se incorporaron cláusulas democráticas, tanto la Unión Europea en el Tratado de Niza de 2001, como en el ámbito interamericano en la Carta Democrática de la OEA de 2001, en el MERCOSUR, en el Protocolo de Ushuaia de 1991, etc. Hoy día la revolución digital produce impactos en el mundo político y jurídico cuyas repercusiones están aún por evaluarse en toda su magnitud, en particular en lo que tiene que ver con la democracia, su concepción y alcance. 
El punto de partida es la universalidad de los derechos humanos que está recogida en la Carta de las Naciones Unidas y ha sido proclamada en su Preámbulo y a lo largo del articulado. Todos los seres humanos sin exclusión o discriminación son titulares de derechos lo que no implica negar las diversidades culturales y regionales. La idea de la universalidad de los derechos humanos es desarrollada en distintos instrumentos como la Declaración Universal de Derechos Humanos del 10 de diciembre de 1948, los Pactos Internacionales de Derechos Humanos y los instrumentos adoptados a nivel europeo y americano. En la Declaración de Viena de 1993 de manera expresa se señala: "Todos los derechos humanos son universales, indivisibles e interdependientes y están relacionados entre sí. La comunidad internacional debe tratar los derechos humanos en forma global y de manera justa y equitativa, en pie de igualdad y dándoles a todos el mismo peso. Debe tenerse en cuenta la importancia de las particularidades nacionales y regionales, así como de los diversos patrimonios históricos, culturales y religiosos, pero los Estados tienen el deber, sean cuales fueran sus sistemas políticos, económicos y culturales, de promover y proteger todos los derechos humanos y libertades fundamentales".

La universalidad de los derechos humanos se basa en la noción misma de persona humana, en la dignidad que la sustenta. Supone que es común a todos y cada uno de nosotros y comprende a los derechos civiles y políticos, económicos, sociales y culturales y a aquellos otros que vayan siendo reconocidos con el devenir del tiempo, así como también las obligaciones correlativas que se generan. Es un proceso continuo.

Los derechos humanos son indivisibles, interdependientes y están interrelacionados; es deber del Estado asegurar su respeto y garantía. Garantía del presente y seguridad en su proyección futura. Lo antes expresado no impide que haya situaciones de enfrentamientos de derechos.

En términos jurídicos el problema que se plantea con las noticias falsas es un conflicto de derechos. En este sentido, cuando se transmite información puede haber tensión e inclusive conflicto con los derechos de las personas que pueden ver afectados sus derechos, por ejemplo, al honor o a la intimidad. ${ }^{7}$ Ello ocurre particularmente cuando se trata de noticias falsas. ¿Como juega la veracidad de la información en este contexto? Veracidad no significa verdad absoluta pero tiene que existir una diligencia debida en el informador en cuanto a la averiguación de los hechos. Diligencia que debe guardar relación directa con el objeto de la noticia, su fuente y posibilidad de ser verificada.

La exactitud o no de la información puede requerir una prueba simple o compleja y el procedimiento puede llevar a que lo dilucide un juez. Inclusive, según los casos, dar lugar a rectificación o respuesta, ${ }^{8}$ siendo prudente reprimir el abuso del ejercicio del referido derecho, teniendo en cuenta que el tiempo quelleve el procedimiento puede tornar el esfuerzo ineficaz. Pero lo que más preocupa en última instancia es que el discurso no se limite innecesariamente por su forma y contenido. Es cierto que lo que está en juego es la verdad, pero ¿quien juzga la verdad? Y hasta qué punto es posible contrastarla.

La desinformación no comprende los errores de información, la sátira o la ironía, así como tampoco las noticias partidistas. Un contenido perjudicial si es legal no puede ser

\footnotetext{
${ }^{7}$ PINO, Carolina. Amigos de la verdad: los límites de las fake news. Revista Uno, marzo 2017.

${ }^{8}$ Corte IDH Opinión Consultiva OC 7/86 de 29 de agosto de 1986. Exigibilidad del derecho de rectificación o respuesta (arts. 14.1, 1.1 y 2 (Convención Americana sobre Derechos Humanos).
} 
considerado dentro de esa categoría y estaría protegido por la libertad de expresión. La libertad de expresión y el derecho de acceso a la información que es su corolario son pilares del "estándar democrático". Como bien señaló la Corte Interamericana de Derechos Humanos en la Opinión Consultiva OC 5/85 si se pierde la libertad de expresión se pone en peligro la vigencia de principios esenciales en una sociedad democrática. Su protección es fundamental para la vigencia del resto de los derechos. Sin libertad de expresión no hay democracia.

70. La libertad de expresión es una piedra angular en la existencia misma de una sociedad democrática. Es indispensable para la formación de la opinión pública. [...] Es en fin, condición para que la comunidad, a la hora de ejercer sus opciones, esté suficientemente informada. Por ende, es posible afirmar que una sociedad que no está bien informada, no es plenamente libre". ${ }^{9}$

Es un derecho individual y colectivo a la vez y comprende la idea de buscar, recibir y difundir informaciones e ideas de toda índole. La evolución jurisprudencial a nivel interamericano referida a este derecho ha sido relativamente reciente pero muy rica como se desprende de los distintos casos. ${ }^{10}$

La desinformación afecta directamente los fundamentos de las sociedades democráticas ya que sin información o con falsedades no se da un control sobre las instituciones ni sobre la gestión. Asimismo se percibe claramente las consecuencias que trae aparejada al más alto nivel como ocurre en las elecciones presidenciales o referéndums o en la determinación de opciones de una población determinada.

\footnotetext{
${ }^{9}$ Corte IDH Opinión Consultiva OC 5/85 del 13 de noviembre de 1985. La Colegiación Obligatoria de Periodistas (arts. 13 y 29 Convención Americana sobre Derechos Humanos).

${ }^{10}$ Corte IDH La Última Tentación de Cristo (Olmedo Bustos y otros) vs. Chile. (Fondo, reparaciones y costas. Sentencia de 5 de febrero de 2001. Serie C n. ${ }^{\circ} 73$; caso Yvcher Bronstein vs. Perú. Reparaciones y costas. Sentencia de 6 de febrero de 2001. Serie C n. ${ }^{\circ} 74$; caso Herrera Ulloa vs. Costa Rica. Excepciones preliminares, fondo reparaciones y costas. Sentencia de 2 de julio de 2004 . Serie C n. ${ }^{\circ} 107$; caso Ricardo Canese vs. Paraguay. Fondo, reparaciones y costas. Sentencia de 31 de agosto de 2004. Serie C n. ${ }^{\circ} 111$; caso Palamara Iribarne vs. Chile. Fondo, reparaciones y costas. Sentencia de 22 de noviembre de 2005. Serie C n. ${ }^{\circ} 135$; caso Claude Reyes y otros. Fondo, reparaciones y costas. Sentencia de 19 de septiembre de 2006. Serie C n. ${ }^{\circ} 151$; caso Kimel vs. Argentina. Fondo, reparaciones y costas. Sentencia de 2 de mayo de 2008 Serie C n. ${ }^{\circ}$ 177; caso Tristán Donoso vs. Panamá. Excepción preliminar, fondo, reparaciones y costas. Sentencia de 27 de enero de 2009. Serie C n. ${ }^{\circ}$ 193; caso Ríos y otros vs. Venezuela. Excepciones preliminares, fondo, reparaciones y costas. Sentencia de 28 de enero de 2009. Serie C n. ${ }^{\circ} 194$; caso Perozo y otros vs. Venezuela. Excepciones preliminares, fondo, reparaciones y costas. Sentencia de 28 de enero de 2009. Serie C n. ${ }^{\circ}$ 195; caso Usón Ramírez vs. Venezuela. Excepción preliminar, fondo, reparaciones y costas. Sentencia de 20 de noviembre de 2009. Serie C n. ${ }^{\circ}$ 207; caso Gomes Lund y otros (Guerilha do Araguaia) vs. Brasil. Excepciones preliminares, fondo, reparaciones y costas. Sentencia de 24 de noviembre de 2010. Serie C n. ${ }^{\circ}$ 219; caso Fontevecchia y D’Amico vs. Argentina. Fondo, reparaciones y costas. Sentencia de 29 de noviembre de 2011. Serie C n. ${ }^{\circ} 238$; caso Vélez Restrepo y familiares vs. Colombia. Excepción preliminar, fondo, reparaciones y costas. Sentencia de 3 de septiembre de 2012. Serie C n. ${ }^{\circ}$ 248; caso Uzcátegui y otros vs. Venezuela. Fondo y reparaciones. Sentencia de 3 de septiembre de 2012. Serie C n. ${ }^{\circ}$ 249; caso Mémoli vs. Argentina. Excepciones y preliminares. Fondo, reparaciones y costas. Sentencia de 22 de agosto de 2013. Serie C n. ${ }^{\circ}$ 265; caso Norín Catrimán y otros (dirigentes miembros y activistas del Pueblo Indígena Mapuche) vs. Chile. Fondo, reparaciones y costas. Sentencia de 29 de mayo de 2014. Serie C n. ${ }^{\circ} 279$; caso López Lone y otros vs. Honduras. Excepción preliminar, fondo, reparaciones y costas. Sentencia de 5 de octubre de 2015. Serie C n. ${ }^{\circ} 302$; caso Granier y otros (Radio Caracas Televisión) vs. Venezuela. Excepciones preliminares, fondo, reparaciones y costas. Sentencia de 22 de junio de 2015. Serie C n. 293.
} 
Investigadores del MIT demostraron que las noticias falsas tienen 70\% más de probabilidad de ser compartidas y en consecuencia creídas por quien las lee que una noticia verídica. La muestra comprendió 126.000 noticias compartidas por más de tres millones de usuarios durante los años 2006 y $2007 .^{11}$

¿Cuál ha sido la respuesta de la comunidad internacional a este desafío que presentan las noticias falsas?

El tema es objeto de inquietud tanto a nivel universal como regional. En este sentido, el Relator Especial de las Naciones Unidas (ONU) para la Libertad de Opinión y de Expresión, la Representante para la Libertad de los Medios de Comunicación de la Organización para la Seguridad y la Cooperación en Europa (OSCE), el Relator Especial de la OEA para la Libertad de Expresión y la Relatora Especial sobre Libertad de Expresión y Acceso a la Información de la Comisión Africana de Derechos Humanos y de los Pueblos (CAD HP) adoptaron una declaración al respecto. En efecto, la Declaración Conjunta sobre Libertad de Expresión y «Noticias Falsas» (Fake News), Desinformación y Propaganda de 3 de marzo de $2017^{12}$ refleja la preocupación por la creciente propagación de la desinformación y propaganda que a menudo se implementan con la finalidad de confundir a la población e interferir en su derecho a saber y buscar, recibir y transmitir información, lo que se impide es la formación de opinión propia. Los Relatores Especiales son concientes del peligro que significa suprimir la libre circulación de ideas y el disenso bajo el pretexto de combatir la desinformación y propaganda. Caer en la censura a los medios de comunicación, lesionar el derecho a la libertad de expresión es ir contra las bases de una sociedad democrática. La Declaración se divide en cinco puntos que se refieren a los principios generales, estándares internacionales y buenas prácticas a ser aplicados por los actores cuando se encuentran ante las noticias falsas. La desinformación lleva al descrédito de las instituciones y al afectar la capacidad de los individuos a adoptar decisiones informadas a quien se perjudica en última instancia es a la democracia.

En este sentido es interesante señalar que el 83\% de los europeos entienden que las noticias falsas representan un problema para la democracia en general, "con toda seguridad» (45\%) o «en cierta medida» (38\%). ${ }^{13}$ Surge de la Declaración Conjunta antes mencionada el interés y la inquietud por la adopción de criterios flexibles para enfrentar la desinformación y la propaganda con el propósito de no afectar el derecho internacional de los derechos humanos.

A nivel regional, la Unión Europea ha tenido distintas iniciativas como la East Stratcom (2015) compuesta por 400 voluntarios que semanalmente publican dos boletines; a través de equipos de evaluadores o fact.-checkers independientes, mediante el uso de herramientas digitales y en particular de la celebración de un compromiso europeo donde se aprobarían medidas comunitarias procediendo de forma similar a las adoptadas en la

11 BLÁZQUEZ, Manuel. «El problema de las noticias falsas: detección y contramedidas». Dpto. Biblioteconomía y Documentación. Universidad Complutense de Madrid.

12 Declaración conjunta sobre libertad de expresión y «noticias falsas», desinformación y propaganda. http://www.osce.org/fom/302796?download=true.

13 http://ec.europa.eu/digital-single-market/en/news/first-findings-eurobarometer-fake-news-andonline-disinformation 
lucha contra los mensaje que fomentan el odio, el racismo y la xenofobia. ${ }^{14}$ En este emprendimiento se adhirieron Twiter, Facebook, Microsoft y Youtube.

El enfoque europeo para combatir la desinformación de la Comisión Europea al Parlamento Europeo ${ }^{15}$ y los principios y objetivos que deben guiar las medidas contra la desinformación son: la transparencia con respecto al origen, producción, difusión y dirección de la información; la diversidad para que los ciudadanos puedan tomar decisiones basadas en un pensamiento crítico; la credibilidad de la información mejorando su trazabilidad y por último mayor alfabetización mediática y amplia participación de las partes interesadas, para lograr soluciones inclusivas.

A nivel individual de los países las reacciones podrían agruparse en dos categorías, aquellos que ven en la adopción de normas un posible riesgo para la libertad de expresión por lo que son sumamente restrictivos al hacerlo y quienes han procurado regular la temática por considerar que la solución requiere de un mayor control y en responsabilizar según los regímenes a distintos actores en el proceso.

Un ejemplo del primer grupo lo tenemos en Estados Unidos. La Primera Enmienda de la Constitución de los Estados Unidos ${ }^{16}$ ampara el derecho a intercambiar ideas y puntos de vista en forma libre. En ella se protege la libertad de religión y de expresión más allá de si las ideas sean discutibles o falsas. Las restricciones o censura previa, que realice el Estado son inconstitucionales. Los requisitos para limitar la libertad de expresión están establecidos por la jurisprudencia. En este sentido en la protección de la libertad de expresión se percibe una evolución, en un primer momento las restricciones se dirigen al discurso que se considera peligroso para «la salud pública, la seguridad o la moral» aunque la aplicación de estos criterios no sea muy clara. ${ }^{17}$

Luego, la Corte Suprema fue consagrando una libertad de expresión prácticamente sin restricciones, los estándares de protección son muy altos como se expresa en distintos $\operatorname{casos}^{18}$ y solo se justifica la prohibición cuando el lenguaje «está dirigido directamente a incitar o producir acciones inminentes castigadas por la ley y es ideal para incitar o producir estas acciones». Este pronunciamiento de la Corte Suprema en el caso Branderburg v Ohio marcó el punto de inflexión.

Cabe, sin embargo, señalar que quienes se ven perjudicados por las noticias falsas tienen recursos jurídicos para iniciar una acción por difamación u otros daños o perjuicios relacionados con la libertad de expresión. Dentro de los países que han adoptado normas

${ }^{14}$ PAUNER, Cristina. Noticias falsas y libertad de expresión e información. El control de los contenidos informativos en la red. P. 305-306.

15 Comunicación de la Comisión al Parlamento Europeo, al Consejo, al Comité Económico y Social Europeo y al Comité de Las Regiones. La lucha contra la desinformación en línea: un enfoque europeo. Bruselas 26/4/2018 COM (2018) 236 final.

${ }^{16}$ Enmienda I. El Congreso no legislará respecto al establecimiento de una religión o a la prohibición del libre ejercicio de la misma; ni impondrá obstáculos a la libertad de expresión o de la prensa, ni coartará el derecho del pueblo para reunirse pacíficamente y para pedir al gobierno la reparación de agravios. Enmiendas a la Constitución de los Estados Unidos de América/biblioteca.libertyfund.org

${ }_{17}$ Schenck, V. United States, 249 U.S. 52 (1919; Debs v. United States, 249 U.S. 211 (1919); Abrams v. United States, 250 U.S. 626 (1918); Gitlow v. The People, 268 U.S. 670-672 (1925).

18 Terminello v. Chicago, 337 U.S. 3 (1949); Branderburg v Ohio, 395 U.S. 447 (1969); New York Times Co v. Sullivan, 376 U.S. Nacional Socialist Party v Village 254 (1964) of Skokie, 432 U.S. 43 (1977). 
específicas para regular la publicación de información falsa encontramos a Alemania y Francia.

Alemania aprobó en 2017 una ley contra la publicación en redes sociales de discursos de odio, pornografía infantil, artículos vinculados al terrorismo e información falsa.

La ley se aplica a los proveedores de servicios de telemedia que cuentan con plataformas con fines de lucro en Internet. Los proveedores de servicios utilizan plataformas de Internet para publicar su propio contenido o intercambiarlo entre los usuarios. Las plataformas pequeñas no están comprendidas en esta norma, es decir, que se trata de redes sociales con más de dos millones de usuarios registrados. Tampoco se aplica a las plataformas de información periodística, ni a las plataformas de comunicación individual o las que publican contenidos específicos. Cuando un proveedor de contenidos recibe más de 100 reclamos o quejas respecto de noticias falsas en su plataforma debe informar respecto de las medidas adoptadas para hacer frente a la situación. El informe es publicado en el periódico gubernamental y en la página de inicio de la red social. El proveedor está obligado a indicar el procedimiento para recibir y tramitar quejas. Se establecen plazos (de 24 hs. o siete días si se requiere investigación) para bloquear el acceso o eliminar el contenido.

La ley, al referirse al contenido ilícito, enumera varios delitos según el Código Penal alemán. Tanto las plataformas de medios sociales como Twitter y Facebook pueden ser castigadas con multas que ascienden hasta 50 millones de euros si no eliminan el contenido antijurídico como sus directores que eventualmente son multados con hasta 5 millones de euros.

Esta ley fue objeto de numerosas críticas tales como ir contra la libertad de expresión; las empresas son responsables por alojar contenidos de terceros y deben decidir acerca de si el contenido viola la ley. Deja de este modo la supervisión en manos de las empresas y no es un juez quien resuelve si se ha violado la libertad de expresión o si se debe dar acceso a la información. Las empresas ante la premura de actuar dado los plazos y multas previstas van seguramente a inclinarse por la eliminación del contenido.

En Francia, si bien existían muchas normas para reprimir la difusión de noticias falsas, ${ }^{19}$ se anunció desde la presidencia la intención de proteger la democracia de la desinformación.

Desde que se adoptó la ley de Fideicomiso de la Economía Digital en el año 2004, las plataformas como anfitriones están obligadas a mantener datos que identifiquen a quienes usan sus servicios. De esa manera la autoridad judicial puede bloquear el acceso al contenido en línea o suprimirlo.

La ley de lucha contra la manipulación de la información de 2018 es insuficiente para eliminar en forma rápida el contenido en línea para que no se difunda; otros proyectos presentados y adoptados ese mismo año pretenden combatir la manipulación de la

${ }^{19}$ La ley de libertad de prensa de 29 de julio de 1881 en su art. 27 sanciona la publicación, difusión o reproducción de noticias falsas que perturben la paz pública con multa. El Código Penal en su art. 2261 sanciona con prisión y multa a quien voluntariamente viole la privacidad de otro por cualquier medio y también la ley de libertad de prensa en el art. 29 se refiere al delito de difamación. Biblioteca del Congreso Nacional de Chile/Asesoría Técnica Parlamentaria. Enero, 2018. La regulación de las «fake news» en el derecho comparado. 
información en la era digital e impedir la difusión durante los períodos preelectorales creando una nueva vía judicial.

La libertad de expresión no debe verse limitada innecesariamente porque ello compromete los cimientos de la democracia. Sin embargo es de señalar que el Tribunal Constitucional español para proteger la reputación o los derechos de otras personas ha establecido algunas restricciones y ha afirmado que si bien las opiniones no están sujetas al juicio de veracidad no pueden tener un contenido ofensivo o injurioso que dañe el honor de una persona, difamándola. Asimismo, el Tribunal Europeo de Derechos Humanos en el Asunto Jiménez Losantos c. España ${ }^{20}$ se refiere a la libertad de expresión, su alcance y límites y a las cuestiones de interés general. La trascendencia de la libertad de expresión e información la hace primar en casos de duda o incertidumbre, pues lo que está en juego es el interés general, el interés público. Las redes sociales como reflejo de la sociedad informan pero no son supervisadas en su accionar. En ese sentido, aún cuando se podría regular en forma más detallada el contenido de la información, especificar las limitaciones de manera más pormenorizada, es preferible optar por la amplitud y la flexibilidad. De lo contrario, se desnaturalizaría la libertad de expresión e información; tarde o temprano puede caerse en la censura y vaciar el discurso de su contenido.

20 Tribunal Europeo de Derechos Humanos. Asunto Jiménez Losantos c. España. Sentencia Estrasburgo 14 de junio de 2016.

34. El TEDH recuerda a continuación los principios fundamentales que se desprenden de sus sentencias referentes al artículo 10 del Convenio.

La libertad de expresión constituye uno de los fundamentos esenciales de una sociedad democrática, una de las condiciones primordiales de su progreso y de la plenitud de cada persona. Sin perjuicio del apartado 2 del artículo 10 del Convenio, no es solo válida para las "informaciones" o "ideas" que se reciben con agrado o que se consideran como inofensivas o indiferentes, sino también para las que hieren, ofenden o inquietan; así lo requiere el pluralismo, la tolerancia y el espíritu de apertura sin los cuales no existe "sociedad democrática" (Handyside c. Reino Unido, 7 de diciembre de 1976, § 49, serie A n. ${ }^{\circ} 24$, y Lindon, Otchakovsky-Laurens y July c. Francia [GC], n. ${ }^{\circ} 21279 / 02$ y 36448/02, § 45). Tal como lo consagra el artículo 10 del Convenio, la libertad de expresión va acompañada de unas excepciones que requieren, sin embargo, una interpretación restrictiva, y la necesidad de limitarla debe determinarse de forma convincente.

35. La prensa juega ciertamente un papel esencial en una sociedad democrática; aun no debiendo rebasar ciertos límites, para amparar especialmente la protección de la reputación y los derechos ajenos; le incumbe, sin embargo, comunicar, en cumplimiento de sus deberes y de sus responsabilidades, informaciones e ideas sobre todas las cuestiones de interés general (De Haes y Gijsels c. Bélgica, 24 de febrero de 1997, § 37, Compendio de sentencias y decisiones 1997-I, Fressoz y Roire c. Francia [GC], n. ${ }^{\circ}$ 29183/95, § 45, CEDH 1999-I y Bédat c. Suiza [GC] n. ${ }^{\circ}$ 56925/08, § 50, 29 de marzo de 2016). En razón a esta función de la prensa, la libertad periodística implica también el posible recurso a una cierta dosis de exageración, incluso de provocación (Gaweda c. Polonia, n. ${ }^{\circ}$ 26229/95, § 34, CEDH 2002-II).

36. El artículo $10 \S 2$ del Convenio subraya que el ejercicio de la libertad de expresión entraña unos "deberes y responsabilidades" aplicables también a los medios de comunicación social, incluso cuando se trata de cuestiones de un gran interés general. Estos deberes y responsabilidades pueden revestir una importancia especial cuando se corre el riesgo de atentar contra la reputación de una persona citada nominalmente y de perjudicar los "derechos ajenos". Así que deben existir unos motivos específicos para poder eximir a los medios de comunicación social de la obligación que habitualmente les incumbe de comprobar unas declaraciones fácticas difamatorias. A este respecto, entran particularmente en juego la naturaleza y el grado de la imputación en cuestión y el saber hasta qué punto pueden razonablemente considerar los medios de comunicación social, las afirmaciones de sus fuentes como creíbles (Pedersen y Baadsgaard c. Dinamarca [GC], n. ${ }^{\circ} 49017 / 99$, § 78, CEDH 2004-XI). 


\section{BIBLIOGRAFÍA CONSULTADA.}

BILINKIS, Santiago. "La verdad no existe pero la mentira sí». Revista La Nación, 2017.

BLATT, Roberto. Historia reciente de la verdad. Turner Publicaciones S.L., setiembre de 2018. Madrid, p. 103-105.

BLÁZQUEZ, Manuel. «El problema de las noticias falsas: detección y contramedidas». Dpto. Biblioteconomía.

MAZZONE, Daniel. El periodismo, un convidado de piedra en el sistema de pesos y contrapesos en Diálogo Político. Konrad Adenauer Stiftung. Ciencia y Política. Montevideo: abril 2016, p. 125 y ss.

MC INTYRE, Lee. Posverdad. Cátedra Teorema. Madrid, p. 31 y ss.

PAUNER, Cristina. Noticias falsas y libertad de expresión e información. El control de los contenidos informativos en la red. P. 305-306.

PINO, Carolina. Amigos de la verdad: los límites de las fake news. Revista Uno, marzo 2017.

THOMPSON, John. Los medios y la modernidad. Una teoría de los medios de comunicación. Barcelona: Paidós, 1998, p. 15 y ss.

Documentación. Universidad Complutense de Madrid.

Fecha de recepción: 1 de noviembre 2019.

Fecha de aceptación: 30 noviembre 2019. 